\title{
Critical Constructability Principles for Girder Bridge Construction in Malaysia
}

\author{
Chu Sheng Ding ${ }^{1,2}$, Hafez Salleh ${ }^{1 *}$, Mei Ye Kho ${ }^{1}$ \\ ${ }^{1}$ Centre for Building, Construction \& Tropical (BuCTA), Faculty of Built Environment, \\ University of Malaya, 50603 Kuala Lumpur, MALAYSIA \\ ${ }^{2}$ Quantity Surveying Department, Faculty of Built Environment, \\ University College of Technology Sarawak, 96000 Sibu, Sarawak, MALAYSIA \\ * Corresponding Author
}

DOI: https://doi.org/10.30880/ijscet.2019.10.02.004

Received 05 August 2019; Accepted 11 December 2019; Available online 31 December 2019

\begin{abstract}
Implementing constructability concepts in a project can bring many benefits such as reduced project cost \& duration, enhanced project quality, and improved site management. There were numerous research on the constructability concept since its introduction in late 1970. However, there are limited studies that identified the critical constructability principles for infrastructure projects. This study identified the critical design stage constructability principles for girder type river bridge construction in Malaysia. Based on extensive literature review and unstructured interviews with the experts in bridge construction, 54 constructability principles were identified. Questionnaires were distributed to professional engineers and G6 \& G7 contractors in Malaysia to rate the 54 constructability principles in term of their importance or impact in enhancing the constructability of bridge construction based on 5-point Likert scale. The received 143 responses were analysed using factor analysis which is a data reduction tool of SPSS. Varimax method of orthogonal approach was adopted for factor rotation. Factor analysis had helped to generate 11 principal components or critical constructability principles. Cronbach's Alpha reliability test also indicated good reliability of the questionnaire scale. The identified critical constructability principles can provide guidelines to the construction practitioners at the design stage to enhance the performance of bridge construction.
\end{abstract}

Keywords: Constructability principles; buildability principles; bridge construction

\section{Introduction}

It is important that the constructability concepts are adopted to improve projects' performances. Some of the benefits of "constructability" identified by previous researchers include reduced project duration \& cost (Jadidoleslami, Saghatforoush, Heravi, \& Preece, 2018), reduced changes (Saghatforoush, Hassim, Jaafar, \& Trigunarsyah, 2010), better design (Khan, 2018), and improved construction efficiency (Sanjaya, Joni, \& Frederika, 2019). Although there were numerous research on the constructability concept since its introduction in late 1970, there are limited contemporary literature to study the critical constructability principles for infrastructure projects. In the Malaysian context, a few researchers (Hassan, 2005; Jelodar, 2009; Nawi et al., 2009; Mydin, Zin, Majid, Zahidi, \& Memon, 2011) had pointed out that the research on constructability are limited. Therefore, this paper aims to identify the most critical constructability principles for girder type river bridge projects in Malaysia. The research process to identify the most critical constructability principles is explained in this paper. 


\section{Literature Review}

\subsection{Definitions of "Constructability" and "Buildability"}

There are many definitions of "constructability" and "buildability". The literature shows that different countries adopt different terms. Generally, "constructability" is more frequently used in Australia and Malaysia whereas "buildability" is adopted by Hong Kong and Singapore. The United States use both terms interchangeably. One of the more recent definitions of "constructability" is:

Constructability is one of the project management methods to evaluate the whole construction process. It is defined as a concept with relative, not absolute, value to increase optimization capacity of resources, such as workforce, time, cost, quality and working environment conditions (JadidAlEslami, Saghatforoush, \& Ravasan, 2018).

Based on the various definitions of constructability, the most frequently used keywords are "integration of construction knowledge/expertise" and "optimum use of construction knowledge and experience". As for buildability, the keywords appear to be "ease of construction". Although constructability and buildability can be used interchangeably (Kannan and Santhi, 2018), differences between them can still be found. The researchers found that buildability concerns more on design (Khan, 2018) whereas constructability encompasses wider scope (Alinaitwe, Nyamutale, \& Tindiwensi, 2014) and it embraces management functions/systems (JadidAlEslami et al., 2018).

\subsection{Constructability Principles}

There are various principles introduced by various institutions or researchers over the past decades. Based on extensive literature review and unstructured interviews with 5 bridge construction experts, 54 design stage constructability principles for girder bridge construction were identified and presented in Table 1.

Table 1 - Constructability principles at the design stage for girder type river bridge projects

\begin{tabular}{|c|c|}
\hline \multicolumn{2}{|r|}{ Constructability Principles } \\
\hline \multicolumn{2}{|r|}{ Principles related to improved design, design simplification and adequate information } \\
\hline 1 & Design easily visualized \\
\hline 2 & Simplify the specifications to achieve efficient construction \\
\hline 3 & Design for less number of assemblies (less construction processes) \\
\hline 4 & Provide detailed and clear design information \\
\hline 5 & Allow for flexibility or interchangeability (e.g. left/right orientation of elements/assemblies) \\
\hline 6 & Conduct design review (to examine possible clashes, ambiguities, unrealistic tolerances etc. in the design) \\
\hline \multicolumn{2}{|r|}{ Principles related to improved design coordination } \\
\hline 7 & Allow individuals with current construction knowledge to involve in the early construction planning \\
\hline 8 & Allow for adequate coordination of designs, plans and specifications \\
\hline \multicolumn{2}{|r|}{ Principles related to standardization \& modularization } \\
\hline 9 & Standardize the project elements/ design for repetitiveness (dimension, material, specification \& shape) \\
\hline 10 & $\begin{array}{l}\text { Design for less variety of trade (e.g. carpentry works, structural steel installation, plastering works, welding } \\
\text { works) }\end{array}$ \\
\hline 11 & Design takes into account the capability of modularization for project elements \\
\hline \multicolumn{2}{|r|}{ Principles related to Prefabrication } \\
\hline 12 & Allowing prefabrication off site \\
\hline 13 & Design maximizes the usage of pre-cast and pre-fabricated elements instead of cast in situ \\
\hline \multicolumn{2}{|r|}{ Principle related to site investigation } \\
\hline 14 & Thorough investigation of the site before design \\
\hline \multicolumn{2}{|r|}{ Principles related to construction method and construction sequence } \\
\hline 15 & Optimal design-originated construction technique/method \\
\hline 16 & Design takes into account the construction sequence \& efficiency \\
\hline 17 & Design reduces the risk of damage to finished work by subsequent operations \\
\hline 18 & Design for minimum time below ground \\
\hline 19 & Designing for safe construction below ground \\
\hline
\end{tabular}


Less wet construction process such as concreting, plastering, etc.

Principles related to construction innovation and sustainable construction

21 Design enabling contractors to develop and adopt alternative construction details/innovative

22 Design to encourage sustainable construction

\section{Principles related to effective site layout/site management}

23 Design takes into account effective site layout

24 Design considers the accessibility of construction personnel, materials and equipment

25 Design takes into account storage requirement at the construction site

26 Design allowing less area allocated at site for storing formwork/falsework

27 Design for lesser environmental nuisance (e.g. dust, noise, vibration, waste water etc.)

28 Design considers water conservation and site drainage solutions

29 Design for the skills available

30 Design to allow economic use of labour

31 Design to avoid return visit by trade (complete certain parts/works with as few return visits as possible)

\section{Principles related to plant and machinery utilization}

32 Design for plant and machinery utilization (use general rather than specific plant, less variety of plant used for the construction of an element)

33 Design considers the availability of plant and equipment.

34 Design for temporary plant and equipment anchorages on the permanent structure (e.g. allow for hoisting point on the permanent structure)

35 Design allows economic use of plant

Principles related to material availability and utilization

36 Consider availability and suitability of designed materials (both local and imported)

37 Design takes into account the use of green materials

38 Contractor's input should be sought in the identifications of preferred materials

39 Design takes into account wastage minimization (e.g. concrete, steel, formwork etc.)

\section{Principles related to components installation}

40 Components easily connected/installed (less complicated fixings)

41 Allow for adaptation on site (e.g. piping layout can be adjusted when facing obstacles)

42 Give flexibility in components/assemblies erection sequence

43 Allowing temporary supports to be removed earlier to clear the working space

44 Allowing sufficient tolerance (e.g. able to accommodate a slight variation in the size/dimension)

Principle related to the use of advanced information technology/ visualization tools

45 Design allows the use of advanced information technology / visualization tools (e.g. BIM software)

\section{$46 \quad$ Investigate the impacts of design on safety}

47 Allowing safe sequence of trades

48 Sizes and weights of materials and components are safe for workers to handle using commonly available plant

49 Design facilitates construction during adverse weather conditions

Principles related to aesthetics

50 The design is aesthetically appealing (design is attractive)

51 The design complements the surrounding environment

\section{Principles related to construction cost and time}

52 The cost is acceptable to the client (value for money)

53 Design takes reasonable time to be built

\section{Principle related to operability and maintainability}

54 Design improves the effectiveness and efficiency of operability (fit for intended use) and maintainability (reduce maintenance works)

\subsection{The Limitation of Previous Constructability Research in Malaysia}

The previous research in Malaysia were mostly focused on building projects. There were limited papers to discuss constructability from the infrastructure perspective. There were only a few papers to discuss the constructability of bridge and highway projects. Based on the in-depth review, it was discovered that there is a trend for the constructability research in overseas countries to shift from the exploration of theoretical constructability concept to the development of quantitative constructability assessment tools/models. A research gap were identified as the existing models were mostly developed for the assessment of building projects. Previous researchers (Ugwu, Anumba, \& Thorpe, 2004; Nourbakhsh et al., 2012; Lam, Wong, Chan, Shea, \& Lau, 2012) had also recommended to extend their 
building design assessment methods to cover infrastructure projects. The researchers of the present paper intend to develop a constructability assessment models for girder bridge construction in the future. The results presented in this research paper contribute a part in achieving the aim. It is expected that the proposed constructability model will (i) fill the gap of literature and (ii) allow the constructability assessment of girder bridge projects at the design stage to be carried out more objectively, systematically, manageable and practically. Furthermore, there is a potential for the developed model to be embedded with Building Information Modelling (BIM) so that automated assessment is made possible and thus contributing to the development of BIM in Malaysia.

\section{Research Methodology}

Extensive literature review was conducted to identify various available design stage constructability principles. Initially, 66 constructability principles were identified. These principles were presented to 5 bridge construction experts for their reviews. Some principles were suggested to be removed due to unsuitability for bridge construction and some principles were suggested to be added. Finally, the total constructability principles were fixed at 54. Questionnaire survey was adopted for the respondents to rate the 54 constructability principles in term of their importance or impact in enhancing the constructability of girder type river bridge projects based on 5-point Likert scale. Number 1 symbolises very low importance or impact on constructability whereas number 5 symbolises very high importance or impact on constructability. The questionnaire was pilot tested on a small sample i.e. 6 contractors and 4 professional engineers. Based on their feedback, some ambiguous wording in the questionnaire were amended prior to the actual survey.

The respondents for this research were professional engineers and G6 \& G7 contractors in Sarawak only. Based on the CIDB contractor list, there are 160 G6 contractors and 687 G7 contractors in Sarawak. As for the professional engineers, there are 431 in Sarawak based on the information given by Board of Engineers Malaysia. Therefore, the total population size in this case is 1278 . The sampling methods adopted were non-probability judgement sampling (purposive sampling) because it is useful to reach specific population with unique characteristics (Pajo, 2018). In this research, the professional engineers and contractors who have experience in bridge construction were first be considered for the questionnaire survey. Although the purposive sampling design is less reliable and generalizable, it is the only viable method to obtain the information from the persons who possess the required information (Sekaran $\&$ Bougie, 2016). Another method adopted was snowball sampling because the researchers did not know enough number of respondents in the area. Under this method, the researchers used the initial respondents to help identify/recommend the other respondents in the target population (Adams \& Lawrence, 2019). This sampling technique is suitable for studies of hard-to-find-populations (Bernard, 2013; Adams \& Lawrence, 2019).

The collected data was analysis using IBM SPSS Statistics version 21. The exploratory factor analysis was used to generate the most critical constructability principles out of the 54 principles available. Factor analysis is a data reduction technique (Pallant, 2016; Black, Babin, \& Anderson, 2018) used "to reduce the number of variables from a larger number to a manageable number of factors for the subsequent analysis (Field, 2018; Aldrich, 2019)." Factor analysis helps to combine variables that are collinear (Field, 2018) and to reduce the number of variables with a minimum loss of information (Hair et al., 2018). The principal component analysis (PCA) in SPSS was used for factor extraction because it is more commonly used (Pallant, 2016; Aldrich, 2019) and more suitable for obtaining "an empirical summary of the data set (Tabachnick \& Fidell, 2018).'

\section{Results and Discussions}

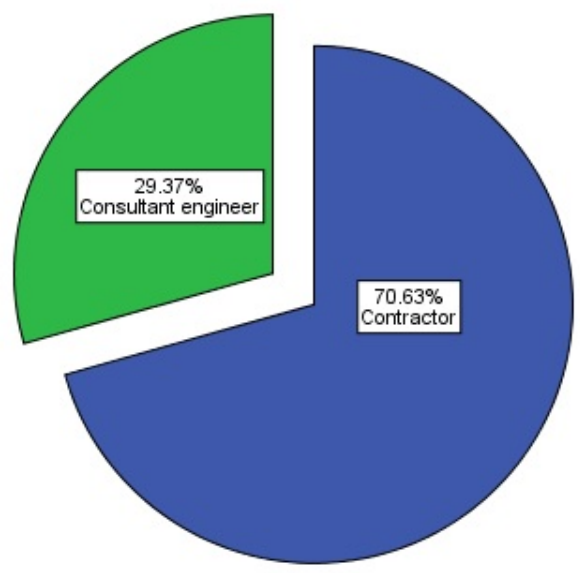

Fig. 1 - Ratio of the respondents for the questionnaire survey 
In total, 560 questionnaires were sent to the targeted respondents. Out of 560 questionnaire distributed, 152 responses were received, representing a $27.1 \%$ response rate. Those responses with missing data were dismissed, resulting in 143 valid responses. Out of 143 responses, 101 (70.63\%) were G6 \& G7 contractors, 42 (29.37\%) were professional engineers (Fig. 1). Thereafter, the sample size calculator in Creative Research Systems website (2012) was used to find the confidence interval of this survey (Fig. 2). The confidence level was set as $95 \%$. It showed that the confidence interval is $7.73 \%$ with 143 responses.



Fig. 2 - Confidence interval of the present survey.

The PCA in SPSS was used to extract the 54 constructability principles. Prior to performing PCA, the suitability of the data for factor analysis was assessed. Inspection of the correlation matrix revealed the presence of many coefficients of .3 and above. As shown in the KMO and Bartlett's Test table below, the Kaiser-Meyer-Olkin value is .849 , exceeding the recommended value of .6 (Tabachnick \& Fidell, 2018; Aldrich, 2019) and Bartlett's Test of Sphericity reaches statistical significance (Sig. value .05 or smaller), supporting the factorability of the correlation matrix (Barlett, 1954; Hair et al., 2018).

KMO and Bartlett's Test

\begin{tabular}{|ll|r|}
\hline Kaiser-Meyer-Olkin Measure of Sampling Adequacy. & .849 \\
Bartlett's Test of & Approx. Chi-Square & 4951.536 \\
Sphericity & df & 1431 \\
& Sig. & .000 \\
\hline
\end{tabular}

As for the factor rotation, Varimax method of orthogonal approach was adopted. Orthogonal approach means that all components are assumed to be uncorrelated (Bordens \& Abbott, 2018; Aldrich, 2019). Varimax rotation method is the most commonly used method which attempts to minimise the number of variables that have high loadings on each other (Pallant, 2016). For the present analysis, rotation converged in 28 iterations. PCA revealed the presence of 14 components with eigenvalues exceeding 1, explaining $72 \%$ of total variance. The percentage of variance for each retained component and its eigenvalue are included in Table 2. Retaining components with eigenvalues of 1 or greater is the most commonly used rule. According to Hinton, McMurray, and Brownlow (2014), "an eigenvalue of 1 means that the factor can explain as much variability in the data as a single original variable." There is no threshold for the minimum percentage of total variance explained but Hair et al. (2018) mentioned that $60 \%$ is satisfactory. Before final decision concerning the number of components to be extracted was made, the rotated component matrix table generated by SPSS was referred to. All principles loaded on all 14 components (Table 2) were carefully studied and it was decided that some components should be removed.

Table 2 - The loadings of constructability principles on the 14 components

\begin{tabular}{ccc}
\hline Principle & Component $1(30.58 \%$ variance explained; Eigenvalue 16.51; Alpha score .882) & Loading \\
Labelled as: Design considers the resources (such as labour and plants) available, \\
utilizes the use of resources, and enhances site accessibility.
\end{tabular}

P32 Design for plant and machinery utilization (use general rather than specific plant, less variety of plant used for the construction of an element)

P31 Design to avoid return visit by trade (complete certain parts/works with as few return $\quad .687$ visits as possible)

P33 Design considers the availability of plant and equipment. $\quad .671$

$\begin{array}{ll}\text { P30 Design to allow economic use of labour } & .639\end{array}$ 
P35 Design allows economic use of plan

P34 Design for temporary plant and equipment anchorages on the permanent structure (e.g.

allow for hoisting point on the permanent structure)

P24 Design considers the accessibility of construction personnel, materials and equipment

P29 Design for the skills available

\begin{tabular}{|c|c|c|}
\hline Principle & $\begin{array}{l}\text { Component } 2(5.55 \% \text { variance explained; Eigenvalue } 3 \text {; Alpha score } .856) \\
\text { Labelled as: Design facilitates early removal of temporary supports and considers } \\
\text { the flexibility, easy installation, adaptation, and slight variation during components } \\
\text { erection. }\end{array}$ & Loadin \\
\hline P43 & Allowing temporary supports to be removed earlier to clear the working space & .766 \\
\hline P41 & Allow for adaptation on site (e.g. piping layout can be adjusted when facing obstacles) & .718 \\
\hline P42 & Give flexibility in components/assemblies erection sequence & .647 \\
\hline P44 & $\begin{array}{l}\text { Allowing sufficient tolerance (e.g. able to accommodate a slight variation in the } \\
\text { size/dimension) }\end{array}$ & 633 \\
\hline P40 & Components easily connected/installed (less complicated fixings) & .423 \\
\hline
\end{tabular}

\begin{tabular}{lll}
\hline Principle & $\begin{array}{l}\text { Component } 3 \text { (4.67\% variance explained; Eigenvalue 2.52; Alpha score .799) } \\
\text { Labelled as: Design complements the surrounding environment, is aesthetically } \\
\text { appealing and allows for innovative and sustainable construction. }\end{array}$ & $\begin{array}{c}\text { Loading } \\
\text { The design complements the surrounding environment }\end{array}$ \\
\hline P51 & The design is aesthetically appealing (design is attractive) & .703 \\
P50 & Design to encourage sustainable construction & .668 \\
P22 & Design takes into account wastage minimization (e.g. concrete, steel, formwork etc.) & .631 \\
P39 & $\begin{array}{l}\text { Design enabling contractors to develop and adopt alternative construction } \\
\text { P21 }\end{array}$ & .630 \\
\end{tabular}

\begin{tabular}{ll}
\hline Principle & $\begin{array}{l}\text { Component } 4 \text { (4.18\% variance explained; Eigenvalue 2.26; Alpha score .888) } \\
\text { Labelled as: Designing for safe construction by considering materials handling, } \\
\text { sequence of trade and impacts of design. }\end{array}$ \\
\hline
\end{tabular}

P48 Sizes and weights of materials and components are safe for workers to handle using $\quad .808$ commonly available plant

$\begin{array}{llr}\text { P47 Allowing safe sequence of trades } & .772\end{array}$

$\begin{array}{ll}\text { P46 Investigate the impacts of design on safety } & .701\end{array}$

\begin{tabular}{|c|c|c|}
\hline Principle & $\begin{array}{l}\text { Component } 5(4.11 \% \text { variance explained; Eigenvalue } 2.22 \text {; Alpha score } .731) \\
\text { Labelled as: Design for simplicity and minimum time below ground by taking into } \\
\text { account the capability of modularization and standardization of project elements. }\end{array}$ & Loading \\
\hline $\mathrm{P} 10$ & $\begin{array}{l}\text { Design for less variety of trade (e.g. carpentry works, structural steel installation, } \\
\text { plastering works, welding works) }\end{array}$ & .696 \\
\hline P3 & Design for less number of assemblies (less construction processes) & .610 \\
\hline P18 & Design for minimum time below ground & .546 \\
\hline P9 & $\begin{array}{l}\text { Standardize the project elements/ design for repetitiveness (dimension, material, } \\
\text { specification \& shape) }\end{array}$ & .498 \\
\hline P11 & Design takes into account the capability of modularization for project elements & .492 \\
\hline $\mathrm{P} 2$ & Simplify the specifications to achieve efficient construction & .418 \\
\hline Principle & $\begin{array}{l}\text { Component } 6(3.35 \% \text { variance explained; Eigenvalue } 1.81 \text {; Alpha score .685) } \\
\text { Labelled as: Design is detailed, clear and easily visualized with less ambiguities and } \\
\text { clashes. }\end{array}$ & Loading \\
\hline $\mathrm{P} 1$ & Design easily visualized & .706 \\
\hline P4 & Provide detailed and clear design information & .703 \\
\hline P6 & $\begin{array}{l}\text { Conduct design review (to examine possible clashes, ambiguities, unrealistic tolerances } \\
\text { etc. in the design) }\end{array}$ & .426 \\
\hline
\end{tabular}




\begin{tabular}{|c|c|c|}
\hline Principle & $\begin{array}{l}\text { Component } 7(3.07 \% \text { variance explained; Eigenvalue 1.66; Alpha score .740) } \\
\text { Labelled as: Design considers environmental impacts, water conservation, site } \\
\text { drainage solutions, storage requirement, and the use of green materials. }\end{array}$ & Loading \\
\hline P28 & Design considers water conservation and site drainage solutions & .777 \\
\hline P27 & Design for lesser environmental nuisance (e.g. dust, noise, vibration, waste water etc.) & .735 \\
\hline P37 & Design takes into account the use of green materials & .593 \\
\hline $\mathrm{P} 25$ & Design takes into account storage requirement at the construction site & .409 \\
\hline Principle & $\begin{array}{l}\text { Component } 8(2.92 \% \text { variance explained; Eigenvalue } 1.58 \text {; Alpha score } .748) \\
\text { Labelled as: Design for efficient construction sequence and method thereby reducing } \\
\text { the risk of damaging finished works }\end{array}$ & Loading \\
\hline P16 & Design takes into account the construction sequence \& efficiency & .727 \\
\hline P15 & Optimal design-originated construction technique/method & .712 \\
\hline P17 & Design reduces the risk of damage to finished work by subsequent operations & .580 \\
\hline Principle & $\begin{array}{l}\text { Component } 9(2.60 \% \text { variance explained; Eigenvalue } 1.41 \text {; Alpha score } .856) \\
\text { Labelled as: Design involves the individuals with current construction knowledge } \\
\text { and allows for adequate coordination of designs, plans and specifications }\end{array}$ & Loading \\
\hline P7 & $\begin{array}{l}\text { Allow individuals with current construction knowledge to involve in the early construction } \\
\text { planning }\end{array}$ & .814 \\
\hline P8 & Allow for adequate coordination of designs, plans and specifications & .801 \\
\hline Principle & $\begin{array}{l}\text { Component } 10(2.52 \% \text { variance explained; Eigenvalue 1.36; Alpha score .687) } \\
\text { Labelled as: Design allows the use of advanced information technology and } \\
\text { maximizes the precast elements and prefabrication off site }\end{array}$ & Loading \\
\hline $\mathrm{P} 13$ & Design maximizes the usage of pre-cast and pre-fabricated elements instead of cast in situ & .773 \\
\hline $\mathrm{P} 12$ & Allowing prefabrication off site & .547 \\
\hline P45 & $\begin{array}{l}\text { Design allows the use of advanced information technology / visualization tools (e.g. BIM } \\
\text { software) }\end{array}$ & .453 \\
\hline Principle & $\begin{array}{l}\text { Component } 11(2.33 \% \text { variance explained; Eigenvalue } 1.26 \text {; Alpha score } .881) \\
\text { Labelled as: Design takes reasonable time and spends acceptable cost to be built }\end{array}$ & Loading \\
\hline $\mathrm{P} 53$ & Design takes reasonable time to be built & .774 \\
\hline P52 & The cost is acceptable to the client (value for money) & .751 \\
\hline Principle & Component 12 (excluded because of three unrelated loadings) & Loading \\
\hline P26 & Design allowing less area allocated at site for storing formwork/falsework & .655 \\
\hline P49 & Design facilitates construction during adverse weather conditions & .516 \\
\hline P19 & Designing for safe construction below ground & .504 \\
\hline Principle & Component 13 (excluded because of one loading only) & Loading \\
\hline P5 & $\begin{array}{l}\text { Allow for flexibility or interchangeability } \\
\text { elements/assemblies) }\end{array}$ & .731 \\
\hline Principle & $\begin{array}{l}\text { Component } 14 \text { (excluded because of two insignificant loadings and unrelated } \\
\text { variables) }\end{array}$ & Loading \\
\hline P54 & $\begin{array}{l}\text { Design improves the effectiveness and efficiency of operability (fit for intended use) and } \\
\text { maintainability (reduce maintenance works) }\end{array}$ & .510 \\
\hline $\mathrm{P} 23$ & Design takes into account effective site layout & .480 \\
\hline
\end{tabular}


Normally, a component should have at least 3 variables (or 3 principles in this research) for it to be retained (Yong \& Pearce, 2013; Pallant, 2016; Tabachnick \& Fidell, 2018). However, Component 9 and 11 were retained for the present research. According to Yong and Pearce (2013), "a factor with 2 variables is only considered reliable when the variables are highly correlated with each another $(r>.70)$ but fairly uncorrelated with other variables."

Therefore, the correlation matrix generated by SPSS was referred to. For component 9, the correlation between P7 and P8 was .748 whereas for component 11, the correlation between P52 and P53 was .788. Component 12 was excluded because three unrelated principles were loaded together (Pallant, 2016). P19 "Designing for safe construction below ground" was unrelated to P26 and P49. Although P26 and P49 may be related, the correlation between them was weak (.334). Component 13 was excluded because a component must have at least 2 variables (Raubenheimer, 2004; Yong \& Pearce, 2013). Component 14 was excluded because there was only two principles loaded on it and the correlation between them was weak (.316). Therefore, there are 11 valid components. After the number of components to retain was decided, the next step was to look at the content of the principles in each component. Then the components were labelled (Field, 2018; Aldrich, 2019) to cover all the relevant principles. Table 2 shows the components that had been labelled.

\subsection{Reliability Analysis}

Reliability means that a measure should consistently reflect the construct it is measuring (Aldrich, 2019). The Cronbach's alpha reliability analysis was done using SPSS to test the reliability of the questionnaire used. For the present study, the reliability analysis was run for each component, so there were 11 analyses in total. The following tables show the summary of the reliability test for the principles fall under component 1 :

Item-Total Statistics

\begin{tabular}{|l|r|r|r|r|r|}
\hline & $\begin{array}{c}\text { Scale Mean if } \\
\text { Item Deleted }\end{array}$ & $\begin{array}{c}\text { Scale } \\
\text { Variance if } \\
\text { Item Deleted }\end{array}$ & $\begin{array}{c}\text { Corrected } \\
\text { Item-Total } \\
\text { Correlation }\end{array}$ & $\begin{array}{c}\text { Squared } \\
\text { Multiple } \\
\text { Correlation }\end{array}$ & $\begin{array}{c}\text { Cronbach's } \\
\text { Alpha if Item } \\
\text { Deleted }\end{array}$ \\
\hline P24 & 26.5385 & 19.419 & .631 & .411 & .870 \\
P29 & 26.6573 & 18.762 & .605 & .443 & .873 \\
P30 & 26.8252 & 18.159 & .669 & .534 & .866 \\
P31 & 26.8601 & 18.854 & .668 & .506 & .866 \\
P32 & 26.6853 & 19.400 & .665 & .525 & .867 \\
P33 & 26.6783 & 19.318 & .642 & .520 & .869 \\
P34 & 26.9930 & 18.599 & .640 & .447 & .869 \\
P35 & 26.8741 & 18.477 & .688 & .535 & .864 \\
\hline
\end{tabular}

Reliability Statistics

\begin{tabular}{|c|c|c|}
\hline $\begin{array}{c}\text { Cronbach's } \\
\text { Alpha }\end{array}$ & $\begin{array}{c}\text { Cronbach's } \\
\text { Alpha Based } \\
\text { on } \\
\text { Standardized } \\
\text { Items }\end{array}$ & $\mathrm{N}$ of Items \\
\hline .882 & .884 & 8 \\
\hline
\end{tabular}

In Item-Total Statistics table, column labelled "Corrected Item-Total Correlation", all the values are above .30 which means that the all items correlate with the overall score from the scale (Field, 2018). As shown in Reliability Statistics table, the Cronbach's Alpha score is .882 which means that the reliability is high. According to Hinton et al. (2014), a score in between .70 to .90 shows high reliability and a score above .90 shows excellent reliability. Next, it can be found that all the values in the column labelled "Cronbach's Alpha if item deleted" are around the same value of the overall Cronbach's Alpha score (.882). According Field (2018), an item should be deleted if it has a value that is significantly higher than the overall Alpha score. As such, no items should be deleted to improve the reliability score for component 1 .

For the present research, most alpha scores of the 11 components fall in between .70 to 90 (Table 2), indicating good reliability. Good reliability means that if the questionnaires are to be completed by the same participants at another time, the similar results could be obtained. Moreover, all figures in the "Cronbach's Alpha if item deleted" columns for all the 11 components are around the same value of the overall Cronbach's Alpha scores. This indicates that all items are positively contributing to the overall reliability.

\section{Conclusion}


Questionnaire survey was adopted for the professional engineers and contractors to rate the 54 constructability principles in term of their importance or impact in enhancing the constructability of girder type river bridge projects based on 5-point Likert scale. The responses of questionnaire survey were analysed using principal component analysis of SPSS software. This helped to consolidate numerous principles into 14 components/critical constructability principles. Out of this 14 components, 3 components were excluded due to unsuitability. A total of 11 components (or consolidated principles) as followings were identified:

Principle 1: Design considers the resources available, utilization of resources and site accessibility.

Principle 2: Design facilitates early removal of temporary supports and considers the flexibility, easy installation, adaptation, and slight variation during components erection.

Principle 3: Design complements the surrounding environment, is aesthetically appealing and allows for innovative and sustainable construction.

Principle 4: Designing for safe construction by considering materials handling, sequence of trade and impacts of design.

Principle 5: Design for simplicity and minimum time below ground by taking into account the capability of modularization and standardization of project elements

Principle 6: Design is detailed, clear and easily visualized with less ambiguities and clashes.

Principle 7: Design considers environmental impacts, water conservation, site drainage solutions, storage requirement, and the use of green materials.

Principle 8: Design for efficient construction sequence and method thereby reducing the risk of damaging finished works.

Principle 9: Design involves the individuals with current construction knowledge and allows for adequate coordination of designs, plans and specifications.

Principle 10: Design allows the use of advanced information technology and maximizes the precast elements and prefabrication off site.

Principle 11: Design takes reasonable time and spends acceptable cost to be built.

The present study helps to expand the existing literature as it is the first to study the constructability principles for girder type river bridge projects in Malaysia. The 11 principles identified can be considered by the designers when designing girder bridge projects. Many previous researchers supported that implementing constructability principles at the early design stage helps to enhance the effectiveness, efficiency, productivity and performance of a project.

\section{Future direction}

Relying solely on constructability principles for constructability assessment is insufficient because the assessment process are criticised by the previous researchers to be unsystematic, ill-structured and lack of objectivity. Therefore, it is suggested that these 11 critical constructability principles to be included in the future research for the development of quantitative assessment models for girder bridge construction. As mentioned earlier, quantitative models allow the constructability assessment to be carried out more objectively, systematically, manageable and practically.

\section{Acknowledgement}

The work described in this paper was fully supported by University College of Technology Sarawak (UCTS) research grant (UCTS/RESEARCH/2/2019/05).

\section{References}

Adams, K. A., \& Lawrence, E. K. (2019). Research methods, statistics, and application (2nd ed.). California: SAGE Publications, Inc.

Aldrich, J. O. (2019). Using IBM SPSS statistics: an interactive hands-on approach (3rd ed.). California: SAGE Publications Inc.

Alinaitwe, H., Nyamutale, W., \& Tindiwensi, D. (2014). Design phase constructability improvement strategies for highway projects in Uganda. Journal of Construction in Developing Countries, 19(1), 127-140.

Bartlett, M. S. (1954). A note on the multiplying factors for various Chi Square approximations. Journal of the Royal Statistical Society, 16, 296-298.

Bernard, H. R. (2013). Social research methods: qualitative and quantitative approaches (2nd ed.). California: SAGE Publications, Inc. 
Bordens, K. S., \& Abbott, B. B. (2018). Research design and methods: a process approach (10th ed.). New York: McGraw-Hill Education.

Creative Research Systems. (2012). Sample size calculator. Retrieved May 20, 2019, from: https://www.surveysystem.com/sscalc.htm

Field, A. (2018). Discovering Statistics using IBM SPSS Statistics (5th ed.). London: SAGE Publications Ltd.

Hair, J., Black, W., Babin, B., \& Anderson, R. (2018). Multivariate data analysis (8th ed.). Hampshire: Cengage Learning (EMEA) Limited.

Hassan, S. H. (2005). Design phase constructability concepts in highway projects. Master's dissertation, University Teknologi Malaysia.

Hinton, P. R., McMurray, I., \& Brownlow, C. (2014). SPSS explained (2nd ed.). New York: Routledge.

JadidAlEslami, S., Saghatforoush, E., \& Ravasan, A. Z. (2018). Constructability obstacles: an exploratory factor analysis approach. International Journal of Construction Management. doi: 10.1080/15623599.2018.1534044

Jadidoleslami, S., Saghatforoush, E., Heravi, A., \& Preece, C. (2018). Evaluating the existing barriers in implementing constructability. Civil Engineering Journal, 4(12), 2864-2875.

Jelodar, M. B. (2009). Application of constructability concepts in the Industrialised Building System for the Malaysian construction industry. Master's dissertation, Universiti Putra Malaysia.

Kannan, M. R., \& Santhi, M. H. (2018). Automated constructability rating framework for concrete formwork systems using building information modelling. Asian Journal of Civil Engineering, 19(4), 387-413.

Khan, S. (2018). Constructability: A Tool for Project Management. Florida: CRC Press.

Lam, P. T. I., Wong, F. W. H., Chan, A. P. C., Shea, W. C. Y., Lau, J. W. S. (2012). A scheme design buildability assessment model for building projects. Construction Innovation, 12(2), 216-238.

Mydin, S. H., Zin, R. M., Majid, M. Z. A., Zahidi, M., \& Memon, A. H. (2011). Buildability attributes at design phase in Malaysian building construction. International Journal of Sustainable Construction Engineering \& Technology, 2(1), 24-43.

Nawi, M. N. M., Kamar, K. A. M., Abdullah, M. R., Haron, A. T., Lee, A., \& Arif, M. (2009). Enhancement of constructability concept: An experience in offsite Malaysia construction industry. Proceedings of the CIB International Conference on Changing Roles, New Roles and New Challenges. Delft, Netherlands.

Nourbakhsh, M., Mydin, S. H., Zin, R. M., Zolfagharian, S., Irizarry, J., \& Zahidi, M. (2012). A conceptual model to assess the buildability of building structure at design stage in Malaysia. Advanced Materials Research, 446-449, 38793884 .

Pajo, B. (2018). Introduction to research methods: a hands-on approach (1st ed.). California: SAGE Publications, Inc.

Pallant, J. (2016). SPSS survival manual (6th ed.). Queensland: Allen \& Unwin.

Raubenheimer, J. (2004). An item selection procedure to maximise scale reliability and validity. SA Journal of Industrial Psychology, 30(4), 59-64.

Saghatforoush, E., Hassim, S., Jaafar, M. S., \& Trigunarsyah, B. (2010). Critical constructability activities in building projects. Proceedings of the 6th International Project Management Conference. Tehran, Iran.

Sanjaya, P. A., Joni, I. G. P., \& Frederika, A. (2019). The role of contractor in improving buildability in construction projects in Bali. MATEC Web of Conferences, 276, 1-6. 
Sekaran, U., \& Bougie, R. (2016). Research methods for business: a skill-building approach (7th ed.). West Sussex: John Wiley \& Sons Ltd.

Tabachnick, B. G., \& Fidell, L. S. (2018). Using multivariate statistics (7th ed.). New York: Pearson Education Inc.

Ugwu, O. O, Anumba, C. J, Thorpe, A. (2004). The development of cognitive models for constructability assessment in steel frame structures. Advances in Engineering Software, 35(3-4), 191-203.

Yong, A. G., \& Pearce, S. (2013). A beginner's guide to factor analysis: focusing on exploratory factor analysis. Tutorials in Quantitative Methods for Psychology, 9(2), 79-94. 